Anales de Literatura Hispanoamericana

ISSN: 0210-4547

\title{
Mario Vargas Llosa y Francisco Umbral, vidas paralelas y un cordón umbilical: la mujer
}

Ana Godoy Cossío ${ }^{1}$

Resumen. Este artículo muestra el paralelismo entre Mario Vargas Llosa y Francisco Umbral, dos autores contemporáneos, cuyos encuentros bio-bibliográficos en lo vocacional, familiar, personal e íntimo confluyen en un cordón umbilical común: la mujer, como materia prima de sus experiencias totales y de su concepción literaria.

Palabras clave: Mario Vargas Llosa; Francisco Umbral; paralelismo; mujer.

[en] Mario Vargas Llosa y Francisco Umbral, parallel lives and an umbilical cord: the woman

\begin{abstract}
This article shows the parallelism between Mario Vargas Llosa and Francisco Umbral, two contemporary authors whose bio-bibliographical encounters in the vocational, family, personal and intimate fields converge in a common umbilical cord: women, as the raw material of their total experiences and literary conception.
\end{abstract}

Keywords: Mario Vargas Llosa; Francisco Umbral; parallelism; woman.

Cómo citar: Godoy Cossío, A. (2017) Mario Vargas Llosa y Francisco Umbral, vidas paralelas y un cordón umbilical: la mujer, en Anales de Literatura Hispanoamericana 46, 429-438.

Roland Barthes ${ }^{2}$ decía que la obra de Proust "era tan polivalente, se ramifica en tantas direcciones que cuando me acerco a él como crítico me invade una gran modestia y un gran temor. Me parece imposible abordar ese monumento literario" (Baron). Lo mismo he sentido al aproximarme a Francisco Umbral y a Vargas Llosa, dos escritores polivalentes como Proust. Esta tarea comparativa entre dos figuras de la literatura que, a priori, no poseen ningún vínculo parecía impensable porque provienen de distintas latitudes, contextos, experiencias y su narrativa difiere en innumerables aspectos. Al principio tuve la misma sensación de Vargas Llosa cuando comparó los mundos de Onetti y Borges "a simple vista, la distancia entre ambos autores era muy grande" (Vargas Llosa 2015: 102). Sin embargo, pese a esa aparente lejanía, como los kilómetros entre Europa y América, sus vidas y

1 Universidad Complutense de Madrid, España.

E-mail: anngc2005@gmail.com

2 Desde la postura de Barthes: "es la obra lo que encontramos en la vida de Proust [...] La verdad de Proust no se debe a una copia genial de la 'realidad', sino a una reflexión filosófica sobre las esencias y sobre el arte" (Barthes 2003:163). Creemos que esta verdad, también es válida para los autores que estudiamos. 
obras se unen en ciertos puntos comunes a lo largo de la historia literaria, como estaciones obligatorias del tren. Francisco Umbral (España, 1932) y Mario Vargas Llosa (Perú, 1936), escritores contemporáneos nacidos en la misma década vertiginosa y conflictiva del siglo XX son hijos de las guerras mundiales y las dictaduras de Francisco Franco y Manuel A. Odría. Umbral, niño de la posguerra española y Vargas Llosa, niño del Perú "de todas las sangres" y de la heterogénea cultura latinoamericana.

Una síntesis panorámica de sus perfiles, como líneas paralelas equidistantes nos permiten conocer sus voces tutelares, sus modos de concebir no sólo la literatura y la cultura, sino también la vida. La contextura como lectores voraces y autores vocacionales se inicia con los "libros de mamá"3 y con el inmenso bosque de lecturas que fortalecen el árbol genealógico de sus producciones. Ambos han recibido la innegable influencia de los maestros de la literatura francesa del siglo XIX y del XX. Sobre la base de esta tradición se reinventan una nueva forma de captar la realidad para ofrecernos "su verdad, la verdad de la vida que sólo desde el espejo de la ficción nos descubre su grandeza y su miseria” (Díez 2002: 44). Ambos presentan las diversas caras del mundo, a su manera, aunque Mario Vargas Llosa incorpora y renueva su realismo con las técnicas narrativas del siglo XX. Mientras que Umbral refuerza "su tendencia memorialista y perfecciona la escritura del yo, algo muy natural en él" (Martínez 2001: 101), no solo para intentar recuperar su tiempo perdido, a modo de Proust, sino retratar el presente. Sus proyectos literarios empiezan a fluir a principios de los sesenta, todavía bajo las huellas de dos escritores abanderados: Proust para Umbral y Flaubert para Vargas Llosa. También se han servido del banquete de maestros de la literatura española, americana y universal, aparte de la magdalena de Proust: un caracol de Neruda, un pensamiento de Sartre, una mariposa de Nabokov, un verso de Darío, entre otros, según confesaba el propio Quevedo:

Desde esta hora a la de las doce leo en buenos y malos autores; porque no hay ningún libro, por despreciable que sea, que no tenga alguna cosa buena, como ni algún lunar el de mejor nota [...] De unos y de otros procuro aprovecharme de los malos para no seguirlos, y de los buenos para procurar imitarlos (85).

Ambos se inician en los periódicos locales de provincias, Umbral en León y Mario Vargas Llosa en Piura ${ }^{4}$. En 1955, Umbral publica su primer artículo titulado "La mañana" en la revista leonesa Arco: "Ese fue el primer paso que dio hacia la literatura y el reconocimiento con un nuevo nombre que no le recordara de dónde

\footnotetext{
Umbral bautiza con este título un capítulo de su libro Palabras de la Tribu.

4 En realidad, Umbral empieza en El Norte de Castilla con Delibes realizando diversas funciones periodísticas, incluso publicitarias, a parte de la redacción en El Diario de León: "Es significativo que Umbral fuera el primer columnista en exigir una novedad gráfica con la aparición de una caricatura suya cuando dio su primera columna diaria al Diario de León en enero de 1961" (La voz de León 2008: 50). Francisco Umbral, joven periodista, llegó a León, en abril de 1958 y se incorpora a la emisora "La Voz de León" y empieza a publicar sus crónicas en el Diario de León. En esta publicación habría utilizado por primera vez el seudónimo de Francisco Umbral, en la sección nocturna titulada "Buenas noches" (Caballé 2004). El trabajo como mensajero de cables y artículos para el Diario La Crónica, en el que lo ubicó su padre, lo ejercita en el oficio y fortalece sus habilidades periodístico-literarias. Más adelante, colabora por un corto período en la sección de Cultura y Turismo de El Comercio. En París, trabaja para la agencia France Press y para la Radiodifusión Televisión Francesa.
} 
venía, de qué dolor: Francisco Umbral" (Caballé 2012). Casi paralelamente, aunque un poco antes, en 1952, Vargas Llosa se inicia en el Diario La Industria, cuando cursaba el quinto de secundaria en el Colegio San Miguel de Piura. En El pez en el agua recuerda que el director del periódico "especuló sobre cómo podría yo congeniar el trabajo periodístico con las clases del colegio y finalmente tomó su resolución y me contrató" (Vargas Llosa 1993: 214-215). Tras esta primera etapa de aprendizaje periodístico en las provincias, ambos escritores se lanzan a la capital y este paso significará también el gran salto del periodismo a la literatura, a la que consagran su "manera de vivir", como decía Flaubert. Madrid será a Umbral lo que Lima a Vargas Llosa (aunque después él se traslada a Madrid, París y Londres).

A partir de aquí y desde el púlpito fecundo de libertad, los dos escritores se entregan con fervor a la producción literaria, periodística y ensayística, cada uno con sus propias tendencias, vertientes y tradiciones para mostrarnos el complejo telar de conflictos, tensiones socioculturales e ideologías de los imaginarios de España y Perú. Características autenticadas con el inconfundible sello de pasión, obsesión $^{5}$ y desarraigo ${ }^{6}$, otro demonio que parece haberse revertido en material literario: "el proceso de creación narrativa es la transformación del demonio en tema" (Garrido 2007: 265). Ambos representan la figura del escritor comprometido, sobre todo, en las crónicas de diferentes diarios y revistas, como las del Diario El Pais, plataforma donde también han coincidido una temporada. Vargas Llosa, quizás más que Umbral interviene constantemente no sólo en el debate público, sino que sus novelas "lo comprometen [...] involucrándolo por entero en un orbe ficticio que posee la fuerza de persuasión y la complejidad moral [para cambiar la] visión del mundo" (Cercas: 498).

La memoria ha sido el material inagotable de sus producciones y ha contribuido en la autoafirmación de sus personalidades como actos "de reflexión y evocación, ese movimiento del intelecto que reposadamente se entrega a reconstruir una parte de nuestro pasado [...] un ejercicio de aceptación de uno mismo" (Valenzuela: 27). En sus obras se registran dos tipos de memoria que actúa en dos "direcciones distintas pero complementarias: la memoria personal y la memoria colectiva, la evocación de la peripecia individual y la evocación de la peripecia histórica" (García Posada: 11). Umbral asume que gran parte de su obra autobiográfica de la etapa provinciana, directa o indirectamente, "es memorialística [...]. Esto no es monomanía ni pecado peligroso puesto que no podemos escapar del yo y la escritura no es más que una forma de lectura de nosotros mismos" (Umbral 2003: 7). En igual medida, Vargas Llosa afirma: "el punto de partida de todas las cosas que he escrito como ficción, tanto en novelas como en teatro han comenzado siendo experiencias vividas [...]. Creo que en mi caso la imaginación, trabaja

\footnotetext{
"Entre la obsesión de un escritor a nivel individual y el estrato más hondo de la realidad, se establece, pues, un flujo corriente que es decisivo en el nacimiento de toda gran literatura" (Cano Gaviria: 175).

6 En Francisco Umbral, quizás pesa más el sesgo “afectivo" (Gracia 1995). Vargas Llosa confiesa en la entrevista: "el desarraigo, porque nací cambiándome de lugares, casas, de países, de ciudades y eso creo que a mí me ha marcado profundamente en lo que escribo, porque ha sido uno de los grandes demonios, podría decir, uno de los temas recurrentes ¿no? porque mi propia vida, digamos ha sido una realidad profundamente desgarradora. Por ejemplo, salir de Cochabamba para venirme al Perú ha sido una cosa terrible, perder a mis amigos. Yo me sentía peruano. Tenía una gran ilusión de venir al Perú y de repente en Piura todos los chicos de la clase se burlaban por mí porque hablaba como serranito. Me sentía completamente desubicado" (Godoy Cossío 2014).
} 
mucho más sobre recuerdos y sobre imágenes de la memoria que sobre puras invenciones" plantea el problema de su vida entera y que le toca a la edad madura encontrar su solución" (Hellen 2003: 39). Para ellos, la solución ha consistido en el desfogue natural de la memoria, a través de la literatura como "una actividad permanente [...] que uno dedica a escribir, e impregna todos los demás quehaceres, pues la vocación literaria se alimenta de la vida del escritor ni más ni menos que la longínea solitaria de los cuerpos que invade" (Vargas Llosa 2011: 19-20). Además, las rupturas vitales que ambos sufrieron durante la infancia y niñez habrían acrecentado la rebeldía y, por tanto, reforzado su vocación por la escritura "¿Qué origen tiene esa disposición precoz a inventar seres e historias que es el punto de partida de la vocación de escritor? Creo que la respuesta es: la rebeldía. Estoy convencido de que quien se abandona a la elucubración de vidas distintas a aquella que vive en la realidad manifiesta de esta indirecta manera su rechazo y crítica de la vida tal como es, del mundo real, y su deseo de sustituirlos por aquellos que fabrica con su imaginación y sus deseos" (Vargas Llosa 2011: 15). Ésta no es una regla general para todos, pero parece haber sido relevante para ambos.

Los encuentros y desencuentros, ausencias y presencias de sus padres biológicos se habrían convertido en una obsesión literaria y reflejan el complejo de Edipo, cuya puerta de escape ha sido la escritura. Recordemos que: "el mito edípico nutre toda la obra de madurez de Mario Vargas Llosa" (García Posada 1999: 11-12) y también las obras de Umbral, "sublimado en la creación, donde ambas caras se reúnen para darle al creador la unidad que no ha podido alcanzar en su vida real" (Forgues 2009: 344). Para ambos, la literatura ha sido una terapia salvífica que quizás explica el afán permanente de volver al seno materno, a través de sus personajes femeninos, un "eterno retorno" a sus orígenes. "¿Quién es la mujer ideal? ¿Rita, Alma, Enedina o tal vez sencillamente, el "vientre paridor”, "el final uterísimo de la vagina", o sea la que da a luz, la madre?" (Bottin 2010: 189). Quizá esta pregunta es la respuesta que buscamos. Aquí se hallaría la razón fundamental de la abundancia de mujeres en sus obras ${ }^{8}$, vistas desde todos los ángulos posibles e imposibles, accesibles e inaccesibles. No hay mujer ideal: todas representan el inicio. Esta interesante apostilla nos recuerda que la vida/obra son vistas como el "contacto más o menos feliz [...] que rige todo el resto de la vida psíquica del escritor" (Mauron 1969: 76), aunque el Nobel asevera que "no se escriben novelas para contar la vida, sino para transformarla, añadiéndole algo" (Vargas Llosa 2002: 10). Desde este punto, en ellos hay "una titánica lucha interior: la de hombre que ha tenido que hacerse a sí mismo desde la nada, expulsado del paraíso [...] y ha vivido esclavizado por sus demonios interiores, por la obsesión dramática de ser engullido por la nada" (Vargas Llosa 2002: 18). Las primeras etapas de vida son los nudos gordianos donde se funden los límites de sus

\footnotetext{
Godoy Cossío, Ana. Entrevista a Mario Vargas Llosa, Lima, 20/01/2014.

8 Como demostramos, a partir del seguimiento y análisis de los títulos de sus libros: En Umbral: Las vírgenes (1969) Las europeas (1970), Las españolas (1974) Las ninfas (1975), Mis mujeres (1976), Las respetuosas (1976), Las Jais (1977), Los ángeles custodios (1978), Los amores diurnos (1979) A la sombra de las muchachas rojas (1981), Las ánimas del purgatorio (1982), Las señoritas de Aviñón (1995) y otros libros. En Vargas Llosa: La tía Julia y el escribidor (1978), La señorita de Tacna (1981), Elogio de la madrastra (1988), Travesuras de la niña mala (2006) y del amplio abanico de mujeres clasificadas desde diversas perspectivas.
} 
perfiles y confirman las asombrosas coincidencias bio-bibliográficas:

Si uno quiere explicar la génesis de una obra literaria, el porqué esa obra literaria existe y cómo llegó a ser lo que es, es indispensable acudir también a la vida de la persona que escribió esa obra, porque creo que está íntimamente ligado el cómo escribe y el por qué escribe una persona a la vida que ha tenido, a las experiencias que han conformado su vida. (García Márquez 1985: 50).

Una de las cuerdas invisibles y esenciales de este paralelismo es el vacío de la figura paterna en la vida de ambos, es el eslabón que, innegablemente, se ha transmutado en materia prima de su escritura. Vargas Llosa nos confirmó que, sin duda, uno de sus demonios particulares fue la experiencia con su padre, identificado como "el demonio mayor" (Zorrilla 2000: 19). El impacto fue tan fuerte y brutal "yo creí hasta los diez [u] once años que mi padre estaba muerto y de pronto de la noche a la mañana descubrir [sic] que no, que estaba allí, irme a vivir con él, tener una relación dificilísima con él, yo creo que me ha marcado profundamente. Sin duda alguna, ha sido uno de los demonios yo creo más persistente" (Godoy Cossío 2014). Pero la voluntad, el esfuerzo y la rebeldía revirtieron esta situación con el mejor de los resultados: convertirlos en libros. En Francisco Umbral, este hecho es más notorio y menos brutal, pero más profundo y doloroso que, quizás, no ha sido resuelto ni con la literatura, como confesó "el origen de esta mi singularidad literaria habría que buscarlo no en la obra sino en la biografía [de] niño solitario, adolescente en busca de sí mismo [y de] escritor que no se ha encontrado sino en el estilo" (Umbral 1996: 116). Desde el balcón de su memoria literaria y con la lupa de aumento de su personalidad, en sus libros aún percibimos las cenizas del dolor que le quemaban por dentro, el toro del franquismo que ha pisoteado la dignidad de su madre soltera y del hijo bastardo. Un pasado que lo helaba y adormecía su literatura de ironía y sarcasmo.

Este punto de encuentro se fortalece con la gran familia materna que los rodeó y protegió, el clan femenino casi bíblico que, en alguna medida, amortiguó la ausencia del padre. Vargas Llosa recuerda "cuánto extrañaba esa familia que estaba marcada por el número de mujeres [...] esa especie de gran tribu en la que yo pasé mi infancia y el comienzo de la adolescencia [...]. El paraíso feliz" (Godoy Cossío 2014). Aquí, ambas madres criaron a los hijos sin la figura paterna, como madres solteras en un contexto atávico, prejuicioso y represor. Obligadas a cambiar de ciudad y ponerse a salvo del "ambiente hostil". Ana María, madre de Francisco Umbral, se alejó de la provincia y se trasladó a Madrid para "tener a su hijo lejos de Valladolid, lejos de las murmuraciones y sobre todo lejos de la mirada paterna, por el momento cerrada a cal y canto a las consecuencias de su embarazo" (Caballé 2004: 67). Dorita, la madre de Vargas Llosa se fue hacia Arequipa: "mi madre no ponía los pies en la calle, salvo para ir a la iglesia, y se dedicó a cuidar al niño recién nacido" (Vargas Llosa 1993: 18-19). Allí permaneció sólo un año, el entorno adverso la obligó a retornar a Cochabamba, Bolivia junto a la familia materna:

Ese primer año de vida, el único que he pasado en la ciudad donde nací y del que nada recuerdo, fue un año infernal para mi madre, así como para los abuelos y el resto de la familia una familia prototípica de la burguesía arequipeña, en todo lo 
que la expresión tiene de conservador, que compartían la vergüenza de la hija abandonada y, ahora, madre de un hijo sin padre. (Vargas Llosa 1993:18-19).

Los orígenes de la cosmología arquetípica que anida en ellos se hallarían en aquel entorno infantil y provinciano con la madre como eje del paraíso, así como en las huellas mnémicas y las señas de identidad acumuladas de sus concepciones sobre lo femenino. La decisiva presencia materna será la vértebra trascendental en la conformación de sus personalidades y en la configuración de la vocación literaria. En estas etapas, determinantes para la personalidad, los modos de pensar, actuar, sentir y escribir se hallarían las respuestas del cómo y el por qué ambos diseñan a sus personajes, desde sus recuerdos, vivencias, creencias, obsesiones, pasiones y plasman una nueva realidad ficcional, gracias a la recuperación y efervescencia de la memoria voluntaria/involuntaria e individual/colectiva.

Esta ligazón vida/obra constituye nuestro kilómetro cero, desde donde parten el elenco de figuras relevantes de la infancia/adolescencia y desembocan en el mismo océano de arquetipos familiares y sociales de sus libros. En definitiva, la génesis de sus producciones quizá nace de esa "devoción/obsesión por lo femenino" (Umbral 1984: 298) y es la fuerza motora que les impulsa a reinventar ese universo. Como en el Quijote los personajes responden a un canon creativo que, muchas veces, solo se completa con otros ${ }^{9}$, así también los arquetipos femeninos de Vargas Llosa y de Francisco Umbral existen, se reconvierten y se completan a partir de la existencia del narrador-personaje-testigo o desde la "riqueza de personajes [que tienen un] carácter satélite" (Díez 2005: 350). Como en las pinturas de Renoir, en sus textos encontramos mujeres de todas las edades y/o etapas y, al igual que Munch, ambos retratan las obsesiones existenciales más profundas, a través de la mujer idealizada o demonizada, sea madre/hija, niña/mujer. Sin embargo, la mayor confluencia se halla en los arquetipos femeninos familiares: abuelas, madres, tías, primas. A la hora de equilibrar la relevancia de arquetipos, para Umbral será la madre la que tiene el mayor peso en su narrativa, mientras que para Vargas Llosa será la tía. Sin embargo, del otro conjunto de mujeres la mayor concentración recae en tres arquetipos sociales: monjas, criadas y meretrices. En sus obras, ellas conforman los colectivos complejos y polivalentes que fusionan las fronteras sociales, temporales y espaciales de todos los tiempos, porque "el saqueo de la realidad real puede documentarse aún mejor en lo que respecta a los personajes: los modelos [...] o arquetipos permanentes que inspiran verdaderas estirpes" (Vargas Llosa 1971: 108).

En el proceso que ambos han realizado para tallar a los arquetipos femeninos, desde múltiples perspectivas, paradigmas y entornos, sin duda, la pintura, el cine y la música han multiplicado los moldes arquetípicos gestados en el inconsciente colectivo. En muchos casos, ellas tienen un referente real, pero al literaturizarse se inmortalizan; en otros, parten de la ficción, pero se humanizan gracias a sus acciones y a la fuerza de su personalidad. Sabemos que la literatura se nutre tanto de la verdad como de la mentira, funde y confunde, rompe los límites y crea una

9 Es decir, “cada una de las criaturas cervantinas está creada desde y por los otros personajes y así resulta que todos son en todos, todos se pertenecen, y forman entre sí una trabazón densa y firme que es la red de la novela" (Castro 2005: p. XIX). 
nueva verdad literaria. Desde sus telescópicas visiones, los dos autores nos escanean un compendio de mujeres plurales e híbridas, como los seres que abundan en las pinturas de El Bosco. Para redondear mejor la idea de complejidad que reconocemos y proclamamos en los arquetipos femeninos de sus libros, los hemos clasificado en dos: por un lado, son un híbrido compuesto de dos arquetipos: madre-tía, niña-mujer, madre-madrastra, prima-tía que no "se funde en una síntesis superior, [sino] coexisten como elementos diferentes que, sin embargo, sólo alcanzan su plena realidad uno en función del otro" (Vargas Llosa 2011: 148). Por otro, cada mujer es una suma de varios arquetipos adheridos que reflejan las continuas transmutaciones a las que están sometidas en sus entornos, como sucede en la realidad. Sus perfiles se unen como vértices bilaterales, triangulares o circulares que van in crescendo a lo largo de las historias. Cada una es un universo polivalente, en cuya naturaleza se aglutinan otros arquetipos y subsisten en paralelo para complementar sus variados perfiles y mostrarnos los ángulos más realistas y heterogéneos de la sociedad: problemas, ataduras, taras, perversiones, deseos, reflexiones con diversos matices.

La mujer es el cordón umbilical que los enlaza en el territorio común del lenguaje, como "único tapiz del cuarto/monasterio, el idioma, los mil hilos del castellano, hilo femenino y grato de Teresa" (Umbral 1984: 350). Teresa, nombre coincidente de sus primeras novias es la figura representativa y nuclear que sella una vez más el encuentro entre ambos. El perfil novelado de Teresa en Umbral concentra a la niña/muchacha/ninfa/musa/mujer que atraviesa varias facetas que se completan en los diferentes libros: enamorada/novia/esposa, igual que para Vargas Llosa. Teresa simboliza el amor platónico, el primer amor, la novia/adolescente o la futura esposa con la que todos sueñan. Teresa encarna la fruta prohibida y deseada por varios adolescentes, "en un mundo que se desintegra, al hombre solo le queda como tabla de salvación la mujer" (Macías 2012: 36). Como en muchos otros personajes de sus libros, el perfil de Teresa encierra varios arquetipos que se complementan: niña/adolescente/joven/mujer. En definitiva, la mujer es el puerto común al que ambos arriban por distintos caminos.

En el viaje creativo de dos escritores, de mirada intemporal y ecléctica, desde las múltiples dimensiones de la mujer, no se puede hablar de un universo, sino de universos múltiples, porque ambos recalan en uno de los temas más transversales, arraigados e inspiradores: la mujer como sujeto central y leit motiv, presentada como un microcosmos y, a la vez, como un universo complejo. Naturalmente, las protagonistas de ambos escritores también llevan el ADN de todos los arquetipos configurados en las diversas culturas de la literatura universal, porque "el colectivo más destacado en esta sociedad evolucionista es el colectivo femenino" (Umbral 2007). Las protagonistas de Vargas Llosa reflejan las circunstancias socio-políticas y culturales del mundo en general, especialmente occidental, desde el siglo XIX al siglo XX, con predominio en el contexto peruano y latinoamericano. Umbral "retrata a la española del siglo XX desde la señorita educada en una sociedad austera, religiosa y conservadora hasta la joven liberada de la sociedad democrática europeizada, sin omitir el papel del turismo de los años 60 y el impacto de las extranjeras"(Buron-Brun 2010: 15), entre otros arquetipos. En esencia, la mujer como columna vertebral de sus producciones confiere a sus universos la atmósfera imprescindible de realismo, porque "la representación de la mujer implica más que 
la mera descripción física, la pintura ekfrástica en el texto. Figuran también la caracterización (psicológica, cultural, socio-política, etc.), los papeles en que aparecen las mujeres -madres, esposas, amantes, sirvientas- y las actitudes expresadas" (Pérez 1996: 173). La mujer como pasión, sujeto de culto, objeto, como fin, destino o simplemente como inspiración o negación. No sólo como receptora, sino ejecutora y propulsora del cambio: induce, provoca, materializa acciones y reacciones. Desde esta perspectiva, se pone de manifiesto todo el ecosistema psicológico, ético, moral, educacional, sensual y erótico de los autores. En ellos hay un declarado intento de pronunciarse por ellas, para ellas. Hacerlas expresar desde sus galaxias literarias para contar sus miedos, deseos, frustraciones o sueños, como voceras y hacedoras de su mundo y de la historia, a veces mal hecha, como han revelado ambos.

La idea nuclear que presentamos es que los arquetipos femeninos han roto el "techo de cristal" de sus contextos y representan la riqueza que hay en cada mujer, como una alfombra de flores que varía de colores al cambio de las estaciones. Sin duda, la faceta como narradores-locutores de la radio, ha sido un semillero de arquetipos femeninos y una de las columnas que sostiene la cantera de personajes. Podríamos dar muchos ejemplos de sus textos, pero quizás un fragmento de las cartas de François Miterrand a Anne Pingeot, publicadas recientemente, confirma la polivalencia de la mujer en la propia realidad: "Siento hacia ti la ternura total que sin duda exige nuestra extraña condición: el incesto absoluto. Mi hija, mi amante, mi mujer, mi hermana, mi Anne, mi siempre y mi para siempre, mi fuente del fondo de los tiempos" (González 2016).

Este paralelismo entre ambos autores, halla plena justificación porque rompe las fronteras entre dos exponentes de la literatura española e hispanoamericana, referentes imprescindibles de la literatura del siglo XX, cuyas obras no solo cartografían los variados personajes femeninos y contextos, sino también son la manifestación de sus espíritus libres, rebeldes y críticos que buscan verdades, a través de las mentiras de la ficción. En suma, ambos representan las dos caras de un mismo mundo, como dice el propio Nobel: "Siempre he sentido que España y el Perú son como el anverso y el reverso de una misma cosa, y no solo en mi pequeña persona, sino en realidades esenciales como la historia, la lengua y la cultura" (González 2016). Con motivo de homenajear a Cervantes y Shakespeare se nos ha invitado a reflexionar sobre la persistente influencia y sobre los lugares comunes que estos autores fundaron "a tal punto que somos shakesperianos o cervantinos" (Rey 2016). Así también, Vargas Llosa y Francisco Umbral han proyectado el vínculo literario que multiplica las razones de acercamiento entre los dos continentes a partir del denominador común que es la mujer.

\section{Referencias bibliográficas}

Alberca, Manuel. El pacto ambiguo, La novela autobiográfica a la autoficción. Madrid: Biblioteca Nueva, 2007.

Ardavín, Carlos (ed.). Valoración de Francisco Umbral, Ensayos críticos en torno a su obra. Gijón: Libros del Pexe, 2003.

Barón S., Odile. "Proust según Roland Barthes", La Nación, suplemento cultural, 28 de julio de 1999. 
Barthes, Roland. Variaciones sobre la literatura. Buenos Aires: Paidós, 2003.

Bottin, Beatrice, "Un inconfesable encuentro con Alma Mahler", en Mujeres de Umbral. Pau: Université de Pau, 2010.

Buron-Brun Bénédicte de (ed.). Mujeres de Umbral. Pau: Université de Pau/Des de l'Adour/Editions Utriusque Vasconiae: 2010.

Cano Gaviria, Ricardo. El buitre y el ave Fénix. Conversaciones con Mario Vargas Llosa. Barcelona: Anagrama, 1972.

Caballé, Anna. "Esquinas de la estrella umbraliana", Revista Mercurio no. 141 (mayo de 2012).

—El frío de una vida. Madrid: Espasa Calpe, 2004.

Castellani, Jean-Pierre. Francisco Umbral entre literatura y periodismo. Las columnas de prensa. Tours: Université de Tours, 2008.

Castro, Carmen, "Las mujeres del Quijote. Personajes femeninos de Cervantes" en Fanny Rubio (ed.). El Quijote en clave de mujer/es. Madrid: Editorial Complutense, 2005.

Cercas, Javier, "La pregunta de Vargas Llosa", en Mario Vargas Llosa. La ciudad y los perros. Madrid: Real Academia Española/Asociación de Academias de la Lengua Española, 2012.

Díez Fernández, J. Ignacio. "Mujeres sobre fondo gris en el Quijote: la sobrina y el ama", El Quijote en clave de mujer/es, Fanny Rubio (ed.), Madrid, Editorial Complutense, S.A, 2005.

Diez, Luis, G., "Mario Vargas Llosa. La marca del subsuelo", Leer, Año VIII 131 (abril 2002).

Forgues, Roland. Mario Vargas Llosa: Ética y creación. Lima: Editorial Universitaria/Universidad Ricardo Palma, 2009.

García Márquez, Gabriel. Cien años de soledad. Introducción de Mario Vargas Llosa. Barcelona: Bruguera, 1985.

García Posada, Miguel. La rosa y el látigo. Madrid: Espasa Calpe, 1994.

- Mario Vargas Llosa. Una historia no oficial. Madrid: Espasa-Calpe, 1999.

Garriga, José, "La casa verde", en Homo ludens homenaje a Mario Vargas Llosa. Málaga: Ayuntamiento de Málaga, 2007.

Gracia Armendáriz, Juan. El artículo diario de Francisco Umbral (1957-1988): análisis y documentación. Tesis. Madrid: Universidad Complutense de Madrid, 1995.

Godoy Cossío, Ana. Entrevista a Mario Vargas Llosa. Lima 20/01/2014.

González, Enric, "Mi hija, mi amante, mi mujer, mi hermana". El País, 16/10/2016.

Macías Villalobos, Macías, "La novela como retrato de vidas", en El silencio y la palabra. Málaga: Cátedra Vargas Llosa/Universidad de Málaga, 2012.

Martínez, Eduardo. La narrativa de Francisco Umbral. Madrid: Universidad Complutense de Madrid, 2002.

Mauron, Charles, "La psicocrítica y su método", en Tres enfoques de la literatura. Buenos Aires: Carlos Pérez Editor, 1969.

Pérez, Janet I., "Los personajes femeninos pintados por escritores masculinos de la postguerra y después", en Iris M. Zavala (coord.). Breve historia feminista de la literatura española. La literatura española: modos de representación desde el siglo XVIII a la actualidad, vol. 3. Madrid: Anthropos Editorial, 1996.

Quevedo, Francisco de, "Carta moral e instructiva", en Catálogo de Obras escogidas (Manuscritos). Madrid: Biblioteca Nacional, 1997.

Rey, Pedro, "Cervantes y Shakespeare: vidas paralelas de dos viejos contemporáneos", La Nación, 17/04/2016.

Umbral, Francisco. Trilogía de Madrid. Barcelona: Planeta, 1984.

- Los cuadernos de Luis Vives. Barcelona: Planeta, 1996.

- ¿Y cómo eran las ligas de madame Bovary? Barcelona: Destino, 2003.

—Mujeres ya" y "Los placeres y los días", El Mundo, 25/05/2007. 
Valenzuela Garcés, Jorge, "Forma y ficcionalización en los recuerdos en El pez en el agua de Mario Vargas Llosa", Cultura Sur, Revista de Arte y Cultura, nº. 3, Año 2 (2011).

Vargas Llosa, Mario. Historia de un deicidio. Barcelona: Barral editores, 1971.

-El pez en el agua. Barcelona: Seix Barral, 1993.

- "La verdad de las mentiras”, en El autor y su obra. Mario Vargas Llosa. Cursos de verano UCM, 2002.

- La ciudad y los perros. Madrid: Alfaguara, 2011.

- Cartas a un joven novelista. Barcelona: Alfaguara, 2011.

-El viaje a la ficción. Barcelona: Debolsillo, 2015.

Zorrilla, Zein. Vargas Llosa y su demonio mayor: la sombra del padre. Lima: Lluvia Editores, 2000. 